\title{
Pollution and Informal Sector: A Theoretical Analysis
}

\author{
Sarbajit Chaudhuri \\ University of Calcutta \\ Ujjaini Mukhopadhyay \\ University of Calcutta
}

\begin{abstract}
We present a three-sector general equilibrium model with an informal sector, which produces an intermediate input for the formal sector, to analyze the effects of different policies on the environmental standard of the economy. The formal sector is made to pay a pollution emission tax for any pollution level higher than the permissible level that is determined by the regulatory authority. Since the informal manufacturing sector creates pollution, increase in the use of informal sector output in the formal sector raises the level of pollution and widens the discrepancy between actual and permissible levels of pollution, so that the emission tax payable by the formal sector also increases. The efficiency of a representative worker is inversely related to the level of pollution. In this framework, we show that even if the permissible level of pollution is reduced, the polluting informal sector may expand and worsen the environmental standard. On the other hand, an inflow of foreign capital may reduce the pollution level. These results are new in the literature of trade and environment.
\end{abstract}

- JEL classification: O17, O22, O33, O54, Q25, L61

- Keywords: Pollution, Informal sector, Pollution emission tax, Permissible level of pollution, Foreign capital

\footnotetext{
*Corresponding address: Dr. Sarbajit Chaudhuri, 23 Dr. P.N. Guha Road, Belgharia, Kolkata 700083, India. Tel: 91-33-2541-0455 (R), 91-33-2557-5082 (C.U.). Fax: 91-33-2844-1490 (P). E-mail: sarbajitch @yahoo.com, sceco@caluniv.ac.in http://papers.ssrn.com/author=294419 (c2006-Center for International Economics, Sejong Institution, All Rights Reserved.
} 


\section{Introduction}

Of late, environmental pollution has assumed such alarming proportions that it has generated grave concern worldwide. Rampant industrialization and lacuna in environment management have contributed to severe environmental problems in recent years. The issue has become even more prominent in the wake of the world economic order towards a liberalized trade regime. The Uruguay Round of General Agreement on Tariff and Trade (GATT) and the North American Free Trade Agreement (NAFTA) have posed a concern for policymakers regarding the state of natural environment in developing countries under the liberalization regime. It is apprehended that any gains from trade liberalization may be substantially outweighed by the environmental damage in the form of pollution and loss of natural resources that liberalization would engender. This damage to the environment is due to the low environmental standard of developing countries leading to migration of 'dirty' industries there (the 'industrial flight' hypothesis). In addition, these countries may often, purposively, undervalue the environment in order to attract the multinational firms (the 'pollution haven' hypothesis) leading to excessive environmental degradation.

Most countries have undertaken significant measures to protect the environment, and the developed ones have been successful a large extent. But for the developing countries, a major problem in regulating environmental standards is the persistence of the polluting, unregulated informal sector. ${ }^{1}$ The informal sector constitutes a large part of the manufacturing and service sectors and provides most of the employment in the developing countries (Agenor (1996), Cole and Sanders (1985), Majumdar (1993)). Empirical evidence (see for example, Papola (1981), Romatet (1983), Joshi and Joshi (1976)) suggests that the urban informal sector units mostly produce intermediate inputs for the formal manufacturing sector on a subcontracting basis. It also indicates that this sector is a major source of environmental pollution. Many of the formal sector firms delegate the production of components to enterprises on an informal basis through subcontracting. For example, in the city of Kolkata, leather-tanning process is carried out mainly in the informal sector. Similarly, the informal sector participants carry out the process of

\footnotetext{
${ }^{1}$ All enterprises with ten persons or less and engaged in manufacturing, construction, transport, trade, services sector etc. constitute the informal sector. Unlike the formal sector firms, the informal sector units do not get any benefit from the state in the form of tax concessions and they are also outside government regulation.
} 
dyeing for the garments industry on a subcontracting basis. The stages of production that involve environmental pollution are often performed by the informal sector. Thus, it can be argued that a major reason behind environmental degradation accompanying expansion of economic activity in developing countries is the significant presence of the urban informal sector. Usually, legislative authorities adopt two major types of environmental regulation, namely, command and control and economic incentives. In case of command and control, the regulator specifies the steps to control pollution after collecting the necessary information regarding the polluter. Economic incentives can take the form of pollution fees, marketable permits and liability. ${ }^{2}$ However, although these instruments can be implemented for the formal sectors in developed countries, the unregistered informal manufacturing units in developing countries cannot be brought under the purview of government regulation. The informal sector units, often operating under unscientific and unhealthy conditions, contribute significantly in polluting the environment. But they cannot be forced or induced to internalize the environmental costs inflicted on the society primarily due to two reasons. First, these units are unregistered, geographically dispersed and it is quite difficult to identify them. Secondly, the informal sector units with a nominal capital base cannot afford to pay pollution fees or install pollution abating equipments. However, the significant amount of pollution created by them cannot be left unattended.

There is considerable empirical evidence to show that the informal sector activities cause significant environmental pollution. Biller and Quintero (1995) have examined the leather tanneries in Bogota, Colombia. In addition to tanneries they identify the metalworking, electroplating, and textile industries, automobile repair shops, and brick manufacturing as typical informal sector activities causing severe contamination. Blackman and Bannister (1996) have presented the results of an econometric analysis of the diffusion of propane among informal 'traditional' brick-makers in Cd. Juárez, Mexico and suggested that community pressure applied by private-sector trade and neighborhood organizations can generate strong incentives for informal firms to adopt clean technologies. Blackman (1999) has developed a list of feasible environmental management policies.

Among the many alternatives, one possible solution may be to target the formal sector to pay for the external costs of pollution. Most of the informal sector products are used as intermediate goods by the formal sector (for example, in shoe

\footnotetext{
${ }^{2}$ See Kolstad (2000) for more details.
} 
industry, garment industry, etc.). So, if the formal sector is made to pay for its use of the output of the polluting informal sector, it may work as an indirect method of reducing pollution.

We consider a three-sector general equilibrium model with an informal sector, the output of which is used as an intermediate input in the formal sector. We assume that environmental pollution occurs only due to production of goods in the informal sector. The formal sector firms are made to pay a pollution emission tax if the actual level of pollution exceeds a certain permissible limit, which is decided by the pollution regulatory authority. The tax revenue collected from this source is transferred to the workers, since they are the victims of environmental pollution. Labour endowment is measured in efficiency units where the efficiency of a representative worker is inversely related to the level of pollution. So, any change in the actual level of pollution affects the efficiency of the workers and hence affects the effective labour endowment. This again causes a change in the intersectoral output and the level of pollution. An increase in the use of informal sector output as input in the formal sector, raises the level of pollution and widens the discrepancy between actual and permissible levels of pollution, so that the emission taxes payable by the formal sector also increases. In this situation, we show that even if the permissible pollution level is reduced, the informal sector may expand and produce adverse effect on the pollution level of the economy. Next, we analyze the effects of indirect policies like an inflow of foreign capital on the level of pollution of the economy. According to the conventional wisdom an inflow of foreign capital is likely to increase the level of pollution by increasing the size of the formal and informal sectors. But contrary to the common wisdom, we find that an inflow of foreign capital ${ }^{3}$ may actually lower the aggregate level of pollution. These results can at least question the desirability of direct pollution regulation measures like a reduction in the permissible level of pollution in preventing environmental degradation in a developing economy.

\footnotetext{
${ }^{3} \mathrm{An}$ inflow of foreign capital is sometimes accompanied by technology transfer including Environmentally Sound Technology (EST). As a result of foreign direct investment, residents of the host country come into contact with foreign entrepreneurs who possess superior technical skills and knowhow. These new ideas lead to transfer of technology from the foreigners to the residents of the host country and it takes place through observation, discussion and training. This transmission can be considered as a spillover or external effect on the host country. So technology transfer in developing countries takes place mainly through foreign direct investment. However, we here do not consider the case of technology transfer. There is a separate and rich literature in this area. See for example, Mansfield (1961, 1968), Koizumi and Kopecky (1977), Findlay (1978) and Gupta (1998).
} 


\section{The Model}

We consider a small open economy with three sectors operating at close vicinity. Sector 1 produces an agricultural (export) commodity using capital and labour. There are two manufacturing sectors, one formal and another informal. The informal manufacturing sector produces a non-traded input for the formal sector using capital and labor. The formal sector is the tariff-protected import-competing sector producing a manufacturing commodity using capital, labor and the nontraded intermediate input produced by the informal sector. Capital is mobile between the three sectors. On the other hand, labour is perfectly mobile between the agricultural and informal manufacturing sectors. But the formal sector faces an imperfect labour market. It is assumed that labor in the formal sector earns a contractual wage, $W^{*}$, while the wage rate in the informal sector, $W^{*}$, is market determined and $W^{*}>W$. Owing to our small open economy assumption, final commodity prices are taken to be given internationally. The price of the non-traded input produced by the informal sector is determined endogenously. Production functions exhibit constant returns ${ }^{4}$ to scale with diminishing marginal productivity to each factor. The three inputs, capital, labor and the non-traded intermediate input, are fully employed.

The following symbols will be used in the formal presentation of the model.

$a_{K i}=$ capital-output ratio in the ith sector, $i=1,2,3$;

$a_{L i}=$ labour-output ratio in the ith sector, $i=1,2,3$;

$a_{23}=$ amount of intermediate input required to produce 1 unit of commodity 3 ;

$P_{i}=$ world price of the ith good, $i=1,3$;

$P_{2}=$ endogenously determined price of the non-traded input;

$m$ = ad-valorem tariff rate on the import of commodity 3 ;

$h$ = efficiency of each worker;

$W=$ competitive wage rate (in efficiency unit);

$W^{*}=$ unionized wage in the formal sector (in efficiency unit);

$r \quad=$ return to capital;

$X_{i}=$ output level of the ith sector, $i=1,2,3$;

$L \quad=$ labour endowment of the economy in physical unit (normalized to unity);

$K_{D}=$ domestic capital stock of the economy;

$K$ = aggregate capital stock of the economy including foreign capital;

${ }^{4}$ See footnote 8 in this context 
$Z \quad=$ level of pollution in the economy;

$\bar{Z}=$ permissible level of pollution;

$T()=$. aggregate pollution emission tax;

$\theta_{j i}=$ distributive share of the jth input in the ith sector;

$\lambda_{j i}=$ proportion of the jth input employed in the ith sector;

$\wedge \quad=$ proportionate change.

The general equilibrium is represented by the following set of equations:

$$
\begin{gathered}
W a_{L 1}+r a_{K 1}=P_{1} \\
W a_{L 2}+r a_{K 2}=P_{2} \\
W^{*} a_{L 3}+r a_{K 3}+P_{2} a_{23}=P_{2}(1+m)-\frac{T\left(Z\left(X_{2}\right)-\bar{Z}\right)}{X_{3}}
\end{gathered}
$$

The rural sector does not generate any pollution ${ }^{5}$ and without any loss of generality it is assumed that the informal sector is the only polluting sector ${ }^{6}$ so that pollution level, $Z$, is a positive function ${ }^{7}$ of the production level of the informal sector, $X_{2}$, i.e.

$$
Z=Z\left(X_{2}\right) ; Z>0
$$

Even though the informal sector is the only polluting sector, it cannot be brought directly under government regulation simply because it consists mainly of unregistered units. Hence it is only the formal sector, which can be compelled to maintain the environmental standards by making them pay emission tax for the pollution indirectly created by them. Now, let $\bar{Z}$ be the permissible level of pollution, which is a policy parameter of the government. Greater the discrepancy between the permissible level, $\bar{Z}$, and the actual level of pollution, $\bar{Z}$, more is the deterioration in environmental standards and hence higher the aggregate pollution

\footnotetext{
${ }^{5}$ This is only a simplifying assumption. A typical rural sector is assumed to produce a primary exportable commodity. Production of primary exportable commodities also vitiates the environment through use of chemical fertilizers and pesticides. However, the amount of pollution generated by the rural sector is insignificant relative to that produced by the manufacturing sectors.

${ }^{6}$ Qualitative results of the model remain unchanged even if the formal sector is also assumed to produce pollution. As formal manufacturing sector uses an intermediate input produced by the informal sector at a fixed proportion, an expansion of the formal sector implies an expansion of the informal sector. Thus, the qualitative effect of any policy on the informal sector's output (and hence pollution) is equivalent to the case where both the sectors are assumed to generate pollution.

${ }^{7}$ There is no harm in assuming that $Z^{\prime}($.$) is constant. In other words, this means that the level of pollution$ generated by the informal sector firms (industrial emission) is proportional to its output level.
} 
emission tax, $T$, to be borne by the formal sector. This means that the marginal pollution emission tax is positive. Hence,

$$
T=T\left(Z\left(X_{2}\right)-\bar{Z}\right) ; T>0
$$

An effective way to reduce pollution emission tax of formal sector is to cut down on the use of the informal sector output as an input and hence generate lower pollution level. The right-hand side of equation (3) denotes the unit domestic-price of $X_{3}$ net of emission tax where $T\left(Z\left(X_{2}\right)-\bar{Z}\right) / X_{3}$ is the effective emission tax per unit of output that the formal sector has to bear.

Complete utilization of capital in the economy implies that

$$
a_{K 1} X_{1}+a_{K 2} X_{2}+a_{K 3} X_{3}=K
$$

were is the amount of capital employed in the ith sector with $i=1,2,3$.

$X_{2}$ is used entirely for producing $X_{3}$, so that the supply of $X_{2}$ is circumscribed by its total demand by sector 3 . The demand-supply equality condition is given by

$$
a_{23} X_{3}=X_{2}
$$

In equation (7), $\mathrm{a}_{23}$ is assumed to be a constant. This means that to produce one unit of the formal sector's product $a_{23}$ units of the non-traded input are required. ${ }^{8}$

Now, it is assumed that the efficiency of a representative worker, $h$, is inversely related to the level of pollution, $Z$, in the economy. Environmental pollution leads to health hazards, ${ }^{9}$ thus adversely affecting the worker's efficiency. Although in this model only the informal sector creates pollution, it is assumed that pollution affects the efficiency of the entire workforce. This is because all the three sectors operate at close vicinity so that environmental degradation affects all the members of the working class equally. Thus,

\footnotetext{
${ }^{8}$ It rules out the possibility of substitution between the non-traded input and other factors of production in sector 3. Although this is a simplifying assumption, it is not totally unrealistic. In industries like shoe making and garments, large formal sector firms farm out their production to the small informal sector firms under the system of subcontracting. So the production is done in the informal sector firms while labeling, packaging and marketing are done by the formal sector firms. One pair of shoes produced in the informal sector does not change in quantity when it is marketed by the formal sector as a final commodity. Thus there remains a fixed proportion between the use of the intermediary and the quantity of the final commodity produced and marketed by the formal sector. It may be noted that Gupta (1994) and Chaudhuri (2003) have also made this assumption in two different contexts.

${ }^{10}$ Air pollution leads to irritation, breathing problems and lung diseases; water pollution causes contaminated drinking water; improper waste disposal management involves significant human pathogens all these contribute directly to reduce human performance.
} 


$$
h=h\left(Z\left(X_{2}\right)\right) ; h^{\prime}<0
$$

After normalizing the labor endowment in physical units to unity, the fullemployment of labor in efficiency units implies the following:

$$
a_{L 1} X_{1}+a_{L 2} X_{2}+a_{L 3} X_{3}=h\left(Z\left(X_{2}\right)\right)
$$

where $a_{L i} X_{i}$ is the employment of labor in the ith sector in efficiency units for As the labor endowment of the economy in physical units has been normalized to unity, the labor endowment in efficiency units is $h\left(Z\left(X_{2}\right)\right)$.

Throughout the paper, we shall make the following assumptions regarding the relative factor intensities of the different sectors. The agricultural sector is always more labour intensive than the formal manufacturing sector and that the industrial sector as a whole (formal plus informal) is more capital intensive than the agricultural sector in value terms. ${ }^{10}$ The latter implies that the industrial sector is more capital intensive vis-à-vis the agricultural sector in physical terms as well. However, the informal manufacturing sector can independently be either capital intensive or labour intensive relative to the agricultural sector. In this paper, we concentrate only on the case where the agricultural sector is more labor intensive than the informal manufacturing sector. ${ }^{11}$

There are nine endogenous variables in the system: $W, r, X_{1}, X_{2}, X_{3}, h, P_{2}, Z$ and $T$. The parameters of the system are: $P_{1}, P_{2}, K, K_{D}, a_{23}, \bar{Z}, K$ and $m$. There are four variables, $W, r, P_{2}, X_{2}$ and three equations (1), (2) $W$ and $r$ (3) in the price system of the model. This is an indecomposable production system where any change in factor endowment affects factor coefficients and factor prices. By solving equations (1) and (2) $W$ and $r$ can be obtained in terms of $P_{2}$. Substituting the values of $W$ and $\mathrm{r}$ in (3) and solving simultaneously with (6) and (9) and using (7), the values of $X_{1}, X_{2}$ and $P_{2}$ can be obtained. ${ }^{12}$ Having obtained $X_{2}$, one can get $X_{3}$ from (7). Again, $Z$ can be obtained from (4) and $h$ from (8) once $X_{2}$ is obtained. Finally, $T$ can be found from (5), as $Z$ is now known.

\footnotetext{
${ }^{10}$ This assumption is quite realistic and has been extensively used in the theoretical literature on trade and development. See Chandra and Khan (1993), Gupta (1997) and Chaudhuri (2003) in this context.

${ }^{11}$ The informal manufacturing sector being more labor intensive vis-à-vis the agricultural sector is also another possibility. In that case the results of the model hold under different sufficient conditions. Instead of dealing with both the cases, we consider only one case in details, since our main intention is to question the desirability of policies rendering a lower permissible level of pollution. If we can show this by considering just one case, our purpose is served.
} 


\section{Comparative Statics}

According to the conventional wisdom, any policy that entails an improvement in environmental standards is pollution reducing. Thus, a lowering of the permissible level of pollution by the pollution controlling authority definitely seems to be a highly desirable policy. But, in this paper, we reanalyze the efficacy of such a direct environmental policy. We then examine the effect of an inflow of foreign capital ${ }^{13}$ on the environmental situation of the economy.

Total differentials of (1) and (2) and use of envelope conditions ${ }^{14}$ yield:

$$
\begin{aligned}
& \theta_{L 1} \hat{W}+\theta_{K 1} \hat{r}=0 \\
& \theta_{L 2} \hat{W}+\theta_{K 2} \hat{r}=\hat{P}_{2}
\end{aligned}
$$

Solving (10) and (11) by Cramer's rule, one gets the following expressions:

$$
\begin{gathered}
\hat{W}=-\left(\theta_{K 1} \hat{P}_{2}\right) / \mid \theta \\
\hat{r}=\theta_{L 1} \hat{P}_{2} / \mid \theta \\
(\hat{W}-\hat{r})=-\left(\hat{P}_{2} / \mid \theta\right)
\end{gathered}
$$

where,

$|\theta|=\theta_{L 1} \theta_{K 2}-\theta_{K 1} \theta_{L 2}=\theta_{L 1}-\theta_{L 2}>0$ as the agricultural sector is more labor intensive than the informal manufacturing sector.

Now, differentiation of (7), gives

$$
\hat{X}_{3}=\hat{X}_{2}
$$

Assuming the production function of each sector to be of the Cobb-Douglas

\footnotetext{
${ }^{12}$ We should note that $X_{2}$ is nothing but the supply of commodity 2 i.e. $X_{2}^{S}$. Conversely, $a_{23} X_{3}$ in equation (7) gives the demand for the non-traded intermediary i.e. $X_{2}$. Usually, $X_{2}^{D}$ and $X_{2}^{S}$ would not match if one starts from a random $P_{2}$. Therefore, we can define an excess demand function for commodity 2 as: $E\left(P_{2}\right)=X_{2}^{D}\left(P_{2}\right)-X_{2}^{S}\left(P_{2}\right)$. Equation (7) is valid if and only if $E\left(P_{2}\right)=0$ say at $P_{2}=P_{2}^{e}$. For making the entire system consistent, we assume that such a $P_{2}^{e}>0$ exists and it is unique.

${ }^{14}$ Producers in each industry choose techniques of production so as to minimize unit costs. This leads to the condition that the distributive-share weighted averages of changes in input-output coefficients along the unit isoquant in each industry must vanish near the cost-minimization point. This states that an isocost line is tangent to the unit isoquant. In mathematical terms, cost-minimization conditions for the three industries may be written as: $\theta_{L 1} \hat{a}_{L 1}+\theta_{K 1} \hat{a}_{K 1}=0 ; \theta_{L 2} \hat{a}_{L 2}+\theta_{K 2} \hat{a}_{K 2}=0$; and, $\theta_{L 3} \hat{a}_{L 3}+\theta_{K 3} \hat{a}_{K 3}=0$. These are known as the envelope conditions. See Caves, Frankel and Jones (1990), pp.732-38.
} 
type ${ }^{15}$ total differentiation of equations (3), (9) and (6) and use of (12)-(14) and (15) yield, ${ }^{16}$ respectively

$$
\begin{gathered}
\left(\hat{P}_{2} / \mid \theta\right)\left[\theta_{K 3} \theta_{L 1}+\theta_{23}\left(\theta_{L 1}-\theta_{L 2}\right)\right]+\left(\theta_{23} / P_{2} X_{2}\right)\left\{T(.) X_{2}-T(.)\right\} \hat{X}_{2} \\
=\left(\theta_{23} / P_{2} X_{2}\right)(T(.) \bar{Z} \hat{\bar{Z}}) \\
(\hat{P} / \mid \theta)\left[\lambda_{L 1} \theta_{K 1}+\lambda_{L 2} \theta_{K 2}+\lambda_{L 3} \theta_{K 3} \theta_{L 1}\right]=\left\{\lambda_{L 2}+\lambda_{L 3}-h^{\prime}(.) Z(.) X_{2}\right\} \hat{X}_{2}+\lambda_{L 1} \hat{X}_{1}=0 \\
\left(\hat{P}_{2} /|\theta|\right)\left[-\lambda_{K 1} \theta_{L 1}-\lambda_{K 2} \theta_{L 2}-\lambda_{K 3} \theta_{L 3} \theta_{L 1}\right]+\left(\lambda_{K 2}+\lambda_{K 3}\right) \hat{X}_{2}+\lambda_{K 1} \hat{X}_{1}=\hat{K}
\end{gathered}
$$

Solving equations (16) (18) by Cramer's rule the following expressions can be obtained.

$$
\begin{gathered}
\hat{X}_{2}=-(1 /(\Delta \mid \theta))\left[\theta_{K 3} \theta_{L 1}+\theta_{23}\left(\theta_{L 1}-\theta_{L 2}\right)\right] \lambda_{L 1} \hat{K}-\hat{\bar{Z}}\left\{\left(\theta_{23} T(.) \bar{Z}\right) /\left(\Delta|\theta| P_{2} X_{2}\right)\right\} \\
{\left[\lambda_{K 1} \lambda_{L 1}+\lambda_{K 1} \lambda_{L 2} \theta_{K 2}+\lambda_{L 1} \lambda_{K 2} \theta_{L 2}+\theta_{L 1}\left(\lambda_{L 1} \lambda_{L 3} \theta_{K 3}+\lambda_{L 1} \lambda_{K 3} \theta_{L 3}\right)\right]}
\end{gathered}
$$

and,

$$
\begin{gathered}
\hat{P}_{2}=\hat{\bar{Z}}\left[\left\{\left(\theta_{23} T^{\prime}(.) \bar{Z}\right)^{\prime}\left(\Delta P_{2} X_{2}\right)\right\}\left\{\lambda_{K 1}\left(\lambda_{L 2}+\lambda_{L 3}-h^{\prime}(.) Z(.) X_{2}\right)-\lambda_{L 1}\left(\lambda_{K 2}+\lambda_{K 3}\right)\right\}\right] \\
+\hat{K}\left[\left(\lambda_{L 1} \theta_{23}\right)\left\{T(.) Z(.) X_{2}-T(.)\right\} /\left(\Delta P_{2} X_{2}\right)\right]
\end{gathered}
$$

where,

$$
\begin{gathered}
\Delta=1 / \theta\left[\{ \theta _ { K 3 } \theta _ { L 1 } + \theta _ { 2 3 } \theta _ { L 1 } - \theta _ { L 2 } \} \left\{\lambda_{K 1}\left(\lambda_{L 2}+\lambda_{L 3}-h^{\prime}(.) Z(.) X_{2}\right)\right.\right. \\
\left.-\lambda_{L 1}\left(\lambda_{K 2}+\lambda_{K 3}\right)\right]-\left[\theta_{23}\left\{T(.) Z(.) X_{2}-T(.)\right\} /\left(P_{2} X_{2} / \mid \theta\right)\right] \\
{\left[\lambda_{K 1} \lambda_{L 1}+\lambda_{K 1} \lambda_{L 2} \theta_{K 2}+\lambda_{L 1} \lambda_{K 2} \theta_{L 2}+\theta_{L 1}\left(\lambda_{K 1} \lambda_{L 3} \theta_{K 3}+\lambda_{L 1} \lambda_{K 3} \theta_{L 3}\right)\right]}
\end{gathered}
$$

As commodity 2 is a non-traded input, its market must clear domestically and the comparative static exercises are meaningful only if the equilibrium in the market for commodity 2 is stable. It can be checked that the stability condition in the market for the non-traded intermediate input is $\Delta>0 .{ }^{17}$ The necessary condition for $\Delta>0$ is: $\left\{T(.) Z^{\prime} X_{2}<T().\right\}{ }^{18}$

\footnotetext{
${ }^{15}$ This is a simplifying assumption. It implies that the elasticity of substitution between labour and capital in each sector is equal to unity.

${ }^{16}$ See Appendix I for detailed derivation.

${ }^{17}$ Interested readers may check this result or can obtain the mathematical proof from the authors on request.
}

${ }^{18}$ See Appendix II. 
In the stable equilibrium of the market for the non-traded intermediate input, we have: $\Delta>0$ From (19), it follows that $\bar{X}_{2}>0$ when $\bar{Z}<0$; and, $\bar{X}_{2}<0$ when $\hat{K}>0$. Now differentiating equation (4) one gets

$$
Z \bar{Z}=Z(.) X_{2} \bar{X}_{2}
$$

Hence from (22) we find that

$\hat{Z}>0$ when $\hat{\bar{Z}}<0$ and $\hat{Z}<0$ when $\hat{K}>0$. This leads to the following proposition.

Proposition 1: A reduction in the permissible level of pollution in the presence of a polluting informal sector leads to an increase in pollution while an inflow of foreign capital lowers the pollution level in the economy.

To explain these results in economic terms, we first examine the effects of these policies on the effective pollution emission tax rate, say, $F$, where

$$
F=\frac{T\left(Z\left(X_{2}\right)-\bar{Z}\right)}{X_{3}}
$$

Differentiating $F$, using (19) and simplifying we get:19

$$
\begin{gathered}
F \bar{F} X_{3}=-\hat{K}\left\{T(.) Z(.) X_{2}-T(.)\right\}\left[(1 / \Delta|\theta|) \lambda_{L 1}\left\{\theta_{K 3} \theta_{L 1}+\theta_{23}\left(\theta_{L 1}-\theta_{L 2}\right)\right\}\right] \\
-\overline{\bar{Z}}\{T(.) \bar{Z} /(\Delta \mid \theta)\}\left[\{ \theta _ { K 3 } \theta _ { L 1 } + \theta _ { 2 3 } ( \theta _ { L 1 } - \theta _ { L 2 } ) \} \left\{\lambda_{K 1}\left(\lambda_{L 2}+\lambda_{L 3}-h^{\prime}(.) Z(.) X_{2}\right)\right.\right. \\
\left.-\lambda_{L 1}\left(\lambda_{L 2}+\lambda_{K 3}\right)\right]
\end{gathered}
$$

From (23) we find that $\hat{F}>0$ when $\hat{K}>0$; and, $\hat{F}<0$ when $\hat{\bar{Z}}<0$.

If in an attempt to check further deterioration in environmental quality, the pollution control authority fixes the permissible level of pollution at a lower level, $\bar{Z}$ takes a lower value. From equation (23) it follows that the average pollution emission tax that the formal sector has to bear decreases. As a consequence, the effective price of the formal sector's product (net of average emission tax) rises leading to an expansion of the formal sector. As the formal sector uses the output of the informal sector at a fixed rate, the latter sector also expands, thereby raising the pollution level of the society. On the other hand, owing to an inflow of foreign capital the aggregate capital stock of the economy expands. It produces a Rybczynski effect leading to an expansion of the formal sector (also informal

\footnotetext{
${ }^{19}$ For detailed derivation see Appendix III.
} 
manufacturing sector) and a contraction of the agricultural sector as the manufacturing sector as a whole (formal plus informal) is more capital-intensive than the agricultural sector. The average pollution emission tax, $F$, rises and the effective price of the formal sector's product decreases (see equation (23)). This produces a Stolper-Samuelson effect and exerts downward pressure on the output levels of the two manufacturing sectors. So two opposite effects on $X_{3}$ (and hence on $X_{2}$ ) are generated. The negative effect of an increase in $F$ outweighs the positive Rybczynski effect, and $X_{3}$ (and hence $X_{2}$ ) falls as a consequence in the new equilibrium.

\section{Concluding Remarks}

In developed countries reduction of the permissible pollution level by regulating authorities is an effective policy to check environmental degradation. This is due to the fact that increase in the level of pollution beyond the permissible level raises the pollution emission tax to be paid by the formal sector. This induces them to minimize harmful discharges and thus improves the environmental quality. But in developing countries with an informal sector, which cannot be targeted for its polluting activities, such policies of lowering the permissible pollution level may prove ineffective. In this paper, we analyze the desirability of such a policy in a three-sector general equilibrium model with a polluting informal sector, whose output is used as an intermediate input in the formal sector. Higher the use of informal sector product, higher is the pollution created and higher the discrepancy between permissible and actual level of pollution, so that the pollution emission tax payable by the formal sector is also higher. Again, labour endowment is measured in efficiency units where the efficiency of a representative worker is inversely related to the level of pollution. In this situation, we have shown that even if the permissible pollution level is reduced, the polluting sector may expand and affect the environment adversely. Quite evidently, due to its counterintuitive nature this result has very important policy implication. On the contrary, an inflow of foreign capital may be effective in lowering the level of pollution of the economy. These results are new in the literature of trade and environment and can at least question the efficacy of direct pollution preventive measures in bringing down environmental pollution in developing economies.

Received 13 May 2004, Accepted 7 December, 2005 


\section{References}

Agenor, P.R. (1996), "The labor market and economic adjustment", IMF Staff Paper 32, 261-335.

Beladi, H. and Marjit, S. (1992a), "Foreign capital and protectionism", Canadian Journal of Economics 25, 233-38.

Beladi, H. and Marjit, S. (1992b), "Foreign capital, unemployment and national welfare", Japan and the World Economy 4, 311-17.

Biller, D. and Quintero, J.D. (1995), "Policy options to address informal sector contamination in urban Latin America: the case of leather tanneries in Bogota, Colombia", Washington: The World Bank, Latin America Technical Department, Environment Division.

Blackman, A. and Bannister, G.J. (1996), "Community pressure and clean technologies in the informal sector: an econometric analysis of the adoption of propane by traditional brick-makers in Cd. Juárez, Mexico", Discussion Paper 97-16.

Blackman, A. (1999), "Informal sector pollution control: what policy options do we have?" Discussion Paper 00-02.

Brecher, R.A. and Alejandro, C.F. Diaz (1977), "Tariffs, foreign capital and immiserizing growth", Journal of International Economics 7, 317-22.

Caves, R.E., Frankel J.A., and Jones, R.W. (1990), World Trade and Payments (5 ${ }^{\text {th }}$ edition), Scott, Foresman and Little, London: Brown Higher Education.

Chandra,V. and Khan, M. A. (1993), "Foreign investment in the presence of an informal sector", Economica 60, 79-103.

Chaudhuri, S. (2001a), "Foreign capital inflow, technology transfer, and national income", Pakistan Development Review 40(1), 49-56.

Chaudhuri, S. (2001b), "Foreign capital inflow, non-traded intermediate input, urban unemployment and welfare in a small open economy: a theoretical analysis", Pakistan Development Review 40(3), 225-35.

Chaudhuri, S. and Mukherjee, U. (2002a), "Removal of protectionism, foreign investment and welfare in a model of informal sector", Japan and the World Economy, 14(1), 101-16.

Chaudhuri, S. and Mukhopadhyay, U. (2002b), "Economic liberalization and welfare in a model with an informal sector", The Economics of Transition, 10(1), 143-172.

Chaudhuri, S. (2003), "How and how far to liberalize a developing economy with informal sector and factor market distortions", Journal of International Trade and Economic Development 12(4), 403-428.

Cole, W.E. and Sanders, R.D. (1985), "Internal migration and urban employment in the Third World", American Economic Review 75, 481-94.

Findlay, R. (1978), "Relative backwardness, direct foreign investment and the transfer of technology : a simple dynamic model", Quarterly Journal of Economics 92, 1-16.

Grinols, E.L. (1991), "Unemployment and foreign capital: The relative opportunity cost of 
domestic labour and welfare", Economica 57, 107-21.

Gupta, M.R. (1994), "Duty-free zone, unemployment and welfare: a note", Journal of Economics, 59(2).

Gupta, M.R. (1997), "Foreign capital and the informal sector: comments on Chandra and Khan", Economica 64, 353-63.

Gupta, M.R. (1998), "Foreign capital and technology transfer in a dynamic model", Journal of Economics 67, 75-92.

Harris, J.R. and Todaro, M.P. (1970), "Migration, unemployment and development: a twosector analysis", American Economic Review 60, 126-42.

Joshi, H. and Joshi, V. (1976), Surplus Labour and The City: A Study of Bombay, New Delhi Oxford University Press, 1976.

Khan, M.A. (1982), "Tariffs, foreign capital and immiserizing growth with urban unemployment and specific factors of production", Journal of Development Economics 10, 245-56.

Marjit, S. and Beladi, H. (1996), "Protection and gainful effects of foreign capital", Economics Letters 53.

Koizumi, T. and Kopecky, K.J. (1977), "Economic growth, capital movements and the international transfer of technical knowledge", Journal of International Economics 7 , 45-65.

Kolstad C.D. (2000), Environmental Economics, Oxford University Press.

Majumdar, D. (1993), "Labour markets and adjustments in open Asian economies: the Republic of Korea and Malaysia", World Bank Economic Review 7, 349-380.

Mansfield, E.M. (1961), "Technical change and the rate of imitation", Econometrica 29, 741-766.

Mansfield, E.M. (1968), Industrial Research and Technological Innovation, New York, Norton.

Papola, T.S. (1981), Urban Informal Sector in a Developing Economy, New Delhi Vikas Publishing House.

Romatet, E. (1983), "Calcutta's informal sector: theory and reality", Economic and Political Weekly 18 (50), 2115-28.

\section{Mathematical Appendices}

\section{Appendix I:}

Total differentiation of (3) gives

$$
\begin{gathered}
a_{K 3} d r+a_{23} d P_{2}=-\left(a_{23} /\left(X_{2}\right)^{2}\right)\left[X_{2}\left\{T(.)\left(Z(.) d X_{2}-d \bar{Z}\right)\right\}-T(.) d X_{2}\right] \\
\text { or, } \begin{aligned}
\theta_{K 3} \hat{r}+\theta_{23} \hat{P}_{2}=\left(a_{23} /\right. & \left.X_{2} P_{3}(1+m)\right) T(.) \hat{X}_{2}-\left(a_{23} / P_{3}(1+m)\right) T(.) Z(.) \hat{X}_{2} \\
& +a_{23} /\left(X_{2} P_{3}(1+m) T(.) \bar{Z} \overline{\bar{Z}}\right)
\end{aligned}
\end{gathered}
$$


or, $\theta_{K 3} \theta_{L 1}\left(\hat{P}_{2} / \mid \theta\right)+\theta_{23} \hat{P}_{2}=\left(\theta_{23} / P_{2} X_{2}\right) T(.) \bar{X}_{2}-\left(\theta_{23} / P_{2}\right) T() Z.(.) \hat{X}_{2}$

$$
+\left(\theta_{23} / P_{2} X_{2}\right)(T(.) \bar{Z} \hat{\bar{Z}})
$$

or, $\left(\hat{P}_{2} / \mid \theta\right)+\left[\theta_{K 3} \theta_{L 1}+\theta_{23}\left(\theta_{L 1}-\theta_{L 2}\right)\right]+\left(\theta_{23} / P_{2} X_{2}\right) T() Z.(.) \hat{X}_{2}$

$$
=\left(\theta_{23} / P_{2} X_{2}\right)(T(.) \bar{Z} \hat{\bar{Z}})
$$

Again differentiation of (9) yields,

$$
\begin{gathered}
\lambda_{L 1} \hat{X}_{1}+\left(\lambda_{L 2}+\lambda_{L 3}\right) \hat{X}_{2}-h^{\prime}(.) Z(.) X_{2} \hat{X}_{2}=-\lambda_{L 1} \theta_{K 1}(\hat{P} / \mid \theta)-\lambda_{L 2} \theta_{K 2}\left(\hat{P}_{2} / \mid \theta\right) \\
-\lambda_{L 3} \theta_{K 3}\left\{\theta_{L 1} \hat{P}_{1} /|\theta|\right\}
\end{gathered}
$$

Rearranging terms we get

$$
\begin{gathered}
\left(\hat{P}_{2} /|\theta|\right)\left[\lambda_{L 1} \theta_{K 1}+\lambda_{L 2} \theta_{K 2}+\lambda_{L 3} \theta_{K 3} \theta_{L 1}\right]+\left\{\lambda_{L 2}+\lambda_{L 3}-h^{\prime}(.) Z(.) X_{2}\right\} \\
\hat{X}_{2}+\lambda_{L 1} \hat{X}_{1}=0
\end{gathered}
$$

Now differentiation of (6) gives,

$$
\begin{gathered}
\left.\lambda_{K 1} \hat{X}_{1}+\left(\lambda_{K 2}+\lambda_{K 3}\right) \hat{X}_{2}=\hat{K}+\lambda_{K 1} \theta_{L 1}\left(\hat{P}_{2} / \mid \theta\right)+\lambda_{K 2} \theta_{L 2}\left(\hat{P}_{2} / \mid \theta\right)+\lambda_{K 3} \theta_{L 3} \theta_{L 1} \hat{P}_{2} /|\theta|\right\} \\
\quad \text { or, }(\hat{P} /|\theta|)\left[-\lambda_{K 1} \theta_{L 1}-\lambda_{K 2} \theta_{L 2}-\lambda_{K 3} \theta_{L 3} \theta_{L 1}\right]+\left(\lambda_{K 2}+\lambda_{K 3}\right) \hat{X}_{2}+\lambda_{K 1} \hat{X}_{1}=\hat{K}
\end{gathered}
$$

\section{Appendix II:}

Assumptions regarding the relative factor intensities of the different sectors of the economy imply the following mathematical relationships.

$$
\begin{aligned}
& \left(\lambda_{L 1} \lambda_{K 3}-\lambda_{L 3} \lambda_{K 1}\right)>0 ; \\
& \left\{\theta_{L 1}\left(\theta_{K 3}+\theta_{23} \theta_{K 2}\right)-\theta_{K 1}\left(\theta_{L 3}+\theta_{23} \theta_{L 2}\right)\right\}>0 \text { and, } \\
& \left\{\lambda_{K 1}\left(\lambda_{K 3}+\lambda_{23} \lambda_{K 2}\right)-\lambda_{K 1}\left(\lambda_{L 3}+\lambda_{23} \lambda_{L 2}\right)\right\}>0 .
\end{aligned}
$$

From (A.1) the following relationships trivially follow.

$$
\left.\begin{array}{l}
\left\{\theta_{K 3} \theta_{L 1}+\theta_{23}\left(\theta_{L 1}-\theta_{L 2}\right)\right\}>0 ; \text { and, } \\
{\left[\lambda_{K 1}\left\{\lambda_{L 2}+\lambda_{L 3}-\left(h^{\prime}(.) Z X_{2} / h(.)\right)\right\}-\lambda_{L 1}\left(\lambda_{K 2}+\lambda_{K 3}\right)\right]<0}
\end{array}\right\}
$$

As the agricultural sector is more labor intensive than the informal manufacturing sector we also have the following.

$$
|\theta|=\left(\theta_{L 1} \theta_{L 2}>\theta_{L 2} \theta_{K 1}\right) \text { i.e. }\left(\theta_{L 1}>\theta_{L 2}\right) ; \text { and, }\left(\lambda_{L 1} \lambda_{L 2}>\lambda_{L 2} \lambda_{K 1}\right)
$$

The stability of equilibrium of the market for the non-traded intermediate input 
requires that: $\Delta>0$

From (21) we find that:

$$
\begin{gathered}
\Delta=(1 / \theta)\left[\{ \theta _ { K 3 } \theta _ { L 1 } + \theta _ { 2 3 } ( \theta _ { L 1 } - \theta _ { L 2 } ) \} \left\{\lambda_{K 1} \lambda_{K 2}+\lambda_{L 3}-h^{\prime}(.) Z(.) X_{2}\right.\right. \\
\left.\lambda_{L 1}\left(\lambda_{K 2}+\lambda_{K 3}\right)\right]-\left[\theta_{23}\left\{T(.) Z(.) X_{2}-T(.)\right\} /\left(P_{2} X_{2} \mid \theta\right)\right] \\
{\left[\lambda_{K 1} \lambda_{L 1}+\lambda_{K 1} \lambda_{L 2} \theta_{K 2}+\lambda_{L 1} \lambda_{K 2} \theta_{L 2}+\theta_{L 1}\left(\lambda_{K 1} \lambda_{L 3} \theta_{K 3}+\lambda_{L 1} \lambda_{K 3} \theta_{L 3}\right)\right]}
\end{gathered}
$$

Using (A.1)-(A.3) from (21) it is evident that the necessary condition for $\Delta>0$ is: $\left\{T() Z.(.) X_{2}-T().\right\}<0$.

\section{Appendix III:}

The effective emission tax rate is given by

$$
F=\frac{T\left(Z\left(X_{2}\right)-\bar{Z}\right)}{X_{3}}
$$

Differentiating $F$ and using (15), we get

$$
F \hat{F} X_{3}=T(.) Z(.) X_{2} \hat{X}_{2}-T(.) \hat{X}_{2}-T(.) \bar{Z} \hat{\bar{Z}}=\hat{X}_{2}\left\{T(.) Z(.) X_{2}-T(.)\right\}-T(.) \bar{Z} \hat{\bar{Z}}
$$

Now using (19) one gets

$$
\begin{gathered}
F \hat{F} X_{3}=\left\{T(.) Z(.) X_{2}-T(.)\right\}\left[-1 /(\Delta \mid \theta) \lambda_{L 1} K\left\{\theta_{K 3} \theta_{L 1}+\hat{\theta}_{23}\left(\theta_{L 1}-\theta_{L 2}\right)\right\}\right. \\
\left.-\overline{\bar{Z}}\left\{\left(\theta_{23} T(.) \bar{Z}\right)^{\prime}\left(\Delta|\theta| P_{2} X_{2}\right)\right\} C\right]-T(.) \bar{Z} \overline{\bar{Z}}
\end{gathered}
$$

where $C=\left\{\lambda_{K 1} \lambda_{L 1}+\lambda_{K 1} \lambda_{L 2} \theta_{K 2}+\lambda_{L 1} \lambda_{K 2} \theta_{L 2}+\theta_{L 1}\left(\lambda_{K 1} \lambda_{L 3} \theta_{K 3}+\lambda_{L 1} \lambda_{K 3} \theta_{L 3}\right)\right\}$

Simplification yields:

$$
\begin{gathered}
F \hat{F} X_{3}=-\left[T(.) Z(.) X_{2}-T(.)\left(\lambda_{L 1} / \Delta \mid \theta\right)\left\{\theta_{K 3} \theta_{L 1}+\theta_{23}\left(\theta_{L 1}-\theta_{L 2}\right)\right\}\right] \hat{K} \\
-\left\{\left(\theta_{23} T(.) \bar{Z}\right) /\left(\Delta|\theta| P_{2} X_{2}\right)\right\}\left[\left\{T(.) Z(.) X_{2}-T(.)\right\} C+\left\{\left(\Delta|\theta| P_{2} X_{2}\right) / \theta_{23}\right\}\right] \overline{\bar{Z}}
\end{gathered}
$$

Simplifying further and using (A.1) - (A.3) one gets:

$$
F \hat{F} X_{3}=\left\{T^{\prime}(.) Z^{\prime}(.) X_{2}-T(.)\right\}\left[\left(\lambda_{L 1} / \Delta|\theta|\right)\left\{\theta_{K 3} \theta_{L 1}+\theta_{23}\left(\theta_{L 1}-\theta_{L 2}\right)\right\}\right] \hat{K}
$$

$$
(-) \quad(+)(+) \quad(+)
$$$$
-\left\{\left(T^{\prime}(.) \bar{Z}\right) /(\Delta|\theta|)\right\}\left[\{ \theta _ { K 3 } \theta _ { L 1 } + \theta _ { 2 3 } ( \theta _ { L 1 } - \theta _ { L 2 } ) \} \left\{\lambda_{K 1}\left(\lambda_{L 2}+\lambda_{L 3}-h^{\prime}(.) Z^{\prime}(.) X_{2}\right)\right.\right.
$$

$(+) \quad(+)(+)$

$(+)$

$$
\left.\left.-\lambda_{L 1}\left(\lambda_{K 2}+\lambda_{K 3}\right)\right\}\right] \hat{\bar{Z}}
$$

